\title{
LA PARTICIPACIÓN DEL PROCURADOR PÚBLICO EN LOS PROCESOS PENALES POR DELITOS DE CORRUPCIÓN DE FUNCIONARIOS*
}

\author{
THE PARTICIPATION OF THE STATE ATTORNEY IN CRIMINAL \\ PROCEEDINGS FOR OFFENSES OF CORRUPTION OF OFFICIALS \\ A PARTICIPAÇÃO DO MINISTÉRIO PÚBLICO EM PROCESSOS \\ PENAIS POR CRIMES DE CORRUPÇÃO DE FUNCIONÁRIOS
}

\author{
ROSMERY JANET VILLAVICENCIO HEREDIA**
}

Recibido: 30 de noviembre de 2020 - Aceptado: 30 de mayo de 2021-

Publicado: 30 de junio de 2021

DOI: 10.24142/raju.v16n32a6

\section{Resumen}

El presente artículo analiza, por un lado, los daños para el Estado que surgen por la comisión del delito de cohecho y, por otro, la pericia de evaluación económica del daño como instrumento probatorio para la

* $\quad$ El presente estudio se enmarca en la investigación "Magistratura contemporánea: la justicia en el siglo XxI", llevada a cabo ante la Universidad de Jaén (España) y la Academia de la Magistratura (Perú). La línea de investigación gira en torno al proceso penal, siendo el autor el único participante del estudio, así como la fuente de financiamiento es propia. La fecha de inicio del proyecto data del 15 de julio de 2019 y su fecha de culminación fue el 15 de junio de 2020.

** Fiscal Provincial Especializada en Delitos de Corrupción de Funcionarios de la Fiscalía Provincial Corporativa de Lima Este. ORCID: 0000-0002-2940-4514. Correo electrónico: rvillavicenciodj@ mpfn.gob.pe 
determinación del monto indemnizatorio; todo ello desde el derecho penal peruano, para efecto de lograr una adecuada gestión de la prueba en los denominados procesos penales anticorrupción.

Palabras clave: cohecho, daños, indemnización, peritaje, Perú.

\section{Abstract}

This article analyzes, on the one hand, the damages to the State arising from the commission of the crime of bribery, and on the other hand, the expertise of economic evaluation of the damage as a probative instrument for determining the amount of compensation; all this, from the Peruvian criminal law, in order to achieve an adequate management of the evidence in the so-called anti-corruption criminal proceedings.

Keywords: Bribery, Damage, Compensation, Expert evidence, Peru.

\section{Resumo}

Este artigo analisa, por um lado, os danos para o estado decorrentes da prática do crime de suborno e, por outro, a perícia de avaliação econômica do dano como instrumento probatório para determinação do valor da indenização; tudo isso, desde o direito penal peruano, para conseguir uma gestão adequada das provas nos chamados processos penais anticorrupção.

Palavras-chave: suborno, dano, compensação, perícia, Peru. 


\section{INTRODUCCIÓN}

En el Perú se cuenta con el Sistema Administrativo de Defensa Jurídica del Estado - en adelante Sistema- el cual denota el conjunto de principios, normas, procedimientos, técnicas e instrumentos de regulación de la actuación del procurador general del Estado, los procuradores públicos y los demás funcionarios, así como los servidores que ejercen la defensa jurídica del Estado, de conformidad con lo establecido en el numeral 9 del artículo 46 de la ley 29158, Ley Orgánica del Poder Ejecutivo. Este Sistema está regulado en el decreto legislativo 1326, el cual, en su artículo 5, ha indicado lo siguiente:

La defensa jurídica del Estado es la actividad de orden técnico legal que ejercen los/as procuradores/as públicos, en atención a las disposiciones contenidas en el presente decreto legislativo, su reglamento y normas conexas, con la finalidad de aplicarlas en ejercicio de sus funciones acorde con el ordenamiento jurídico vigente.

Ahora bien, el objetivo central de la norma es lograr que judicialmente le fijen un monto económico a la administración pública por concepto de reparación civil, surgida por la comisión del delito, en donde el Estado sea el agraviado; en efecto, el artículo 47.1 del citado decreto legislativo ha establecido que las entidades públicas se constituyen en acreedoras de las reparaciones civiles provenientes de los delitos incurridos en su contra. Asimismo, es de su incumbencia la fijación judicial de la pena de multa, así como su cobro y ejecución efectiva, en virtud del artículo 48.2 de la norma legal en cita, la cual ha indicado que la adecuada percepción de los recursos es de responsabilidad de la Procuraduría Pública que intervino en el proceso, y en los casos donde el Estado no sea el agraviado, le corresponde a la Procuraduría Pública del Instituto Nacional Penitenciario realizar las acciones pertinentes para su cobro.

Frente a ello, para la determinación judicial tanto de la pena de multa como de la reparación civil, el Sistema debe intervenir en el proceso penal correspondiente a través del procurador o el abogado del Estado, quien deberá cumplir con los requisitos señalados en el artículo 29 del decreto legislativo citado. En esa inteligencia, la intervención procesal del procurador es como abogado del Estado agraviado, por lo que tiene a su favor los derechos procesales previstos en el artículo 95 del Código Procesal Penal peruano de 2014 — en adelante CPP-, aumentando sus facultades procesales si se 
constituye en actor civil, de conformidad con los artículos 104 y 105 del CPP, aunque ello implique la prohibición de presentar demanda indemnizatoria en la vía judicial extrapenal, conforme lo establece el artículo 106 del CPP. Ahora bien, la presente investigación gira en torno a la intervención del procurador en los procesos penales que se siguen por el delito de corrupción de funcionarios o cohecho, en el sentido de criticar su actual papel, dado que, si bien en los medios de comunicación peruanos se mencionan los grandes casos anticorrupción, es en virtud de la actuación de las fiscalías especializadas en delitos de corrupción de funcionarios antes que de la Procuraduría. Para ello, consideramos que, si las normas legales le facultan al procurador constituirse en actor civil para una adecuada persecución de la reparación civil, esto no se cumplirá con un procurador pasivo, esperanzado en lo que trabaje el fiscal anticorrupción, así como de un juez que le concede la indemnización, fijándole un monto que se desconoce de dónde surgió y cómo se fundamenta.

En ese orden de ideas, vamos a postular una herramienta procesal que hemos denominado gestión de la prueba, y que permitirá sustentar la imputación del daño y la pericial de evaluación del daño. En efecto, el procurador debe comprender que si anhela una reparación civil a favor del Estado, ello se logrará mediante un adecuado esclarecimiento de los hechos, y para hacerlo se necesita de la prueba, la cual es un ejercicio de razonamiento, reflexión que permitirá fijar los hechos que se pondrán de conocimiento al juez, en concreto las circunstancias de tiempo, modo y lugar; además, permitirá precisar su relevancia jurídica a través de las instituciones de la responsabilidad civil: conducta ilícita, daño, nexo de imputación y factor de atribución. Así, tanto los hechos obtenidos mediante el razonamiento probatorio como su relevancia jurídica, dotan de contenido a la imputación del daño. No obstante, para la cuantificación de la compensación económica se requiere de un instrumento probatorio técnico, como es la pericia de evaluación de daños, que permitirá justificar, por medio del método científico, tanto los conceptos legalmente indemnizables como el monto económico; por lo que esta pericial tampoco es ajena a la gestión de la prueba. En suma, desarrollaremos estas figuras en el marco de la lucha anticorrupción, con la expectativa de que los procuradores tomen conocimiento de dichas herramientas epistémicas y dogmáticas para mejorar su actuación en el proceso penal y así, al lograr esta mejora, aunada con la labor de las fiscalías especializadas, coadyuvar a la eficacia de la lucha antes mencionada. 


\section{GESTIÓN DE LA PRUEBA EN EL DELITO DE CORRUPCIÓN DE FUNCIONARIOS}

El juicio del juez descansa en el juicio del investigador. En ese contexto, el artículo 329.1 del CPP, precisa que el fiscal inicia los actos de investigación cuando tenga conocimiento de la sospecha de la comisión de un hecho que reviste los caracteres de delito, ya sea mediante la investigación de oficio o a petición de los denunciantes; siendo así, el fiscal puede, bajo su dirección, requerir la intervención de la Policía o realizar por sí mismo diligencias preliminares de investigación para determinar si debe formalizar la Investigación Preparatoria (artículo 330.1, CPP); frente a ello, si de la denuncia, del informe policial o de las diligencias preliminares que realizó, aparecen indicios reveladores de la existencia de un delito, que la acción penal no ha prescrito, que se ha individualizado al imputado y que, si fuera el caso, se han satisfecho los requisitos de procedibilidad, la Fiscalía dispondrá la formalización y la continuación de la Investigación Preparatoria (artículo 336.1, CPP); sin embargo, como las diligencias preliminares forman parte de la investigación preparatoria, no podrán repetirse una vez formalizada la investigación, por lo que procede su ampliación si dicha diligencia resultare indispensable, siempre que se advierta un grave defecto en su actuación o que ineludiblemente deba completarse como consecuencia de la incorporación de nuevos elementos de convicción (artículo 337.2, CPP); ahora bien, la norma procesal peruana también faculta al abogado defensor para realizar actos de investigación, de acuerdo con lo señalado en el artículo 84 del CPP; igual facultad detenta el actor civil, de conformidad con el artículo 104 del CPP. Posteriormente, cerrada la investigación, si la Fiscalía decide formular acusación, entonces se dará trámite bajo las reglas de la etapa intermedia, fase que concluye con el auto de citación a juicio (artículo 355, CPP); luego, se realiza la fase de juzgamiento oral (artículo 371, CPP), la cual concluye con su respectiva sentencia (artículo 392, CPP), ingresando el proceso penal a los momentos de impugnación (artículo 401, CPP) y, si fuese el caso, a la ejecución de la sentencia.

Frente a ello, los investigadores no se reducen a la Fiscalía y la Policía, sino que se extienden a los demás sujetos procesales, como es la defensa y el actor civil, para efecto que aporten los elementos de convicción necesarios para el esclarecimiento de los hechos que justifique la toma de decisiones. Este concepto es válido, siguiendo a Prütting (2010, pp. 457-459), tanto para la teoría de la sospecha como para cualquier otra propuesta de estándar 
de prueba, como por ejemplo, la de la carga de la prueba — adjetivada por Nieva (2018, p. 11) como una reliquia histórica-, la de mejor explicación (Laudan, 2007, p. 306), la de capacidad justificativa del acervo probatorio (Ferrer, 2018, p. 404), de las utilidades esperadas (Laudan, 2013, p. 23) o de la inferencia probatoria empírica.

Ahora bien, en la investigación por el delito de cohecho es usual que se reciban los siguientes medios de prueba: 1) la testimonial de aquel ciudadano a quien el funcionario público le está solicitando un beneficio, por lo general económico; o bien de aquel tercero perjudicado por el acto de autoridad emanado de una fuente corrupta; 2) el video o el audio en donde se documenta el acto presumiblemente corrupto; 3) la operación encubierta, incluyendo el marcaje de billetes; 4) el documento que registra el acto de autoridad que presumiblemente haya surgido de una accionar corrupto y 5) los acuerdos de colaboración eficaz. En esa inteligencia, la valoración probatoria sigue las reglas de la denominada prueba indirecta o indiciaria, entendida cuando de la demostración de la existencia de un hecho secundario (hecho probado) sea posible extraer inferencias que fundamenten la hipótesis del hecho principal (hecho por probar o presunto). Así, la prueba indirecta ofrece elementos de confirmación de la hipótesis de existencia de un hecho principal, pero a través de un paso lógico, que parte de un hecho secundario.

En ese orden de ideas, el grado de apoyo de la hipótesis dependerá de la aceptación de la existencia del hecho secundario, es decir, si esta se encuentra lo suficientemente probada, y del grado de aprobación de la inferencia, que se funda en la eficiencia y la suficiencia del hecho secundario, cuya existencia ha sido probada, lo que, por lo general, implica acudir a máximas de experiencia solventes y a argumentos basados en la sana crítica. En conclusión, para determinar el grado de aceptación de la inferencia, que parte del hecho secundario o probado hacia el principal o inferido presuntivamente (hecho por probar), es necesario conocer el criterio en el que dicha inferencia se apoya, que comúnmente son enunciados de carácter general que convencen de la pertinencia y la suficiencia de los indicios para aseverar la hipótesis o conclusión, también conocidos como máximas de experiencia. Así, mientras más preciso y seguro sea el criterio, mayor será el grado de aceptación de la inferencia.

Todo ello lleva a una adecuada gestión de la prueba, es decir, aquella estrategia de recolección y procesamiento de la información para efecto de realizar un razonamiento de corte epistémico sobre los hechos comunicados 
en la noticia criminal; para eso, es importante diferenciar los hechos de su clasificación jurídica. En efecto, ¿qué es un hecho?, ¿qué clases de hechos son los más relevantes para el derecho?, ¿cómo podemos conocer esos hechos?, ¿cómo se relacionan los hechos con las normas?, ¿son los hechos objetivos y neutros o están cargados de teoría?, ¿qué consecuencias tienen para la prueba judicial?, ¿qué es una acción?, ¿qué es una omisión?, ¿cuándo hay una o varias acciones?, ¿cómo se debe argumentar en materia de hechos?, ¿cuándo está suficientemente probado un hecho?, ¿qué importancia tiene la inmediación en la prueba?, ¿cómo se prueban los procesos mentales?, ¿en qué consiste motivar los hechos? Estos y otros interrogantes se ha planteado González (2003, p. 12), reclamando la denominada "falacia normativista", esto es, el habernos dedicado a los problemas de interpretación jurídica antes que al estudio de los hechos.

Al respecto, para Rodríguez (2015, p. 58) la distinción entre hecho y concepto es que los conceptos simbolizan las relaciones empíricas y los fenómenos que vienen afirmados por el hecho; todo hecho se afirma como una relación de conceptos ya que cada término representa el fenómeno descrito por el hecho. Para Bunge (1985, p. 717), el hecho es todo aquello de que se sepa o se suponga que pertenece a la realidad. Para nosotros, los hechos son aquellas circunstancias de tiempo, modo y lugar, que nos permitan conocer un segmento o parcela de la realidad, pero que, por su relevancia jurídica, justifica investigarlos. Ahora bien, en el caso de la lucha anticorrupción, tanto el fiscal como el procurador, en primer lugar, deben proceder a identificar aquellas afirmaciones fácticas principales, las cuales permiten conjeturar que en la situación alegada hay circunstancias potencialmente idóneas para producir los efectos previstos por la norma que se ha usado como criterio de selección y calificación (Benavente, 2011, p. 99). En efecto, con la noticia criminal se debe proceder a construir aquellas afirmaciones fácticas que presentan una idoneidad para conjeturar un caso de cohecho, aunque ello implique el manejo de las categorías dogmáticas de la figura delictiva en cuestión y su diferente taxonomía.

Por otro lado, la gestión de la prueba exige planificar cómo verificar los hechos conjeturados como cohecho; la importancia radica que las afirmaciones fácticas conjeturadas operan como presupuesto de la decisión en el derecho, por ende, su necesidad de probarlos. En ese orden de ideas, y como se indicó en los párrafos anteriores, las fuentes de información en la investigación del cohecho son muy limitadas, debido a que al ser un delito de encuentro, tanto el funcionario como el particular pueden actuar con 
dolo, buscando encubrir sus actos para no perder los beneficios obtenidos por el acto de autoridad corrompido; por tanto, los investigadores tendrán que echar mano de la libertad probatoria que proclama el sistema legal (Benavente, 2017, p. 10 y Ferrer, 2013, p. 22).

Ahora bien, obtenida la información, postulamos que la gestión de la prueba requiere de criterios epistémicos para afianzar con probabilidad las afirmaciones fácticas comunicadas en la noticia criminal, esto es, que está verificada la conjetura de que se está ante un acto de corrupción. Frente a ello, y siguiendo a Coloma (2017, p. 34), tales elementos serían los siguientes: 1) casos en que los criterios son leyes científicas de carácter universal, que se presentan "vulgarizadas", esto es de conocimiento y manejo comúnmente aceptable, a lo que bastará un razonamiento deductivo; 2) casos en que los criterios corresponden a generalizaciones no universales, pero caracterizados por un alto grado de probabilidad, confirmado por una elevada frecuencia estadística; en ese contexto, también es de aplicación el razonamiento deductivo, y 3 ) casos en que los criterios son meras generalizaciones o que denotan la normalidad de determinados acontecimientos o conductas; aquí no es procedente un razonamiento deductivo, sino que más se inclinan a lo que usualmente se conoce como máximas de la experiencia, pero cuya fiabilidad es por imperio de ley, por lo que el operador está autorizado en hacer uso a la hora de construir su razonamiento. Claro está, que desarrollar tales criterios excedería el objetivo del presente estudio.

\section{IMPUTACIÓN DEL DAÑO EN EL DELITO DE CORRUPCIÓN DE FUNCIONARIOS}

La gestión de la prueba parte de entender que si desde la noticia criminal, la Fiscalía identifica una víctima, tendrá que localizarla, informarle sus derechos y lograr que se defina quién va a ser su asesor jurídico; y si esa víctima es el Estado, como ocurre en el delito de corrupción de funcionarios, entonces se tendrá que poner de conocimiento de la investigación al procurador, por lo que sería inadmisible cualquier audiencia ante el órgano jurisdiccional sin que el procurador sea notificado, salvo en aquellos casos en que la ley expresamente determine su no notificación para una audiencia concreta; ella es la logicidad que subyace a las sanciones procesales en contra del procurador ausente en las audiencias, que abandone la asesoría o la misma es deficiente, porque la idea es que esté notificado y acuda a las audiencias para una defensa idónea de los derechos del Estado agraviado. 
Ahora bien, la presencia del procurador en las audiencias exige una gestión del caso materializada en la denominada imputación del daño, esto es, la precisión del marco fáctico, circunstanciado en tiempo, modo y lugar, cuya explicación con claridad y sencillez se desprenda de las evidencias. No debe ser una limitante la exposición del Ministerio Público, porque la sencillez está presente en resaltar aquellos datos fácticos que hagan más entendible el caso, pero, sobre todo, que sobresalten al juez, en términos de que no es cualquier conducta, sino una que le ha causado a su patrocinado daños, sean tangibles o intangibles (el recurrir al famoso adagio: "que no le quepa duda"); porque la sencillez está presente en subsanar alguna omisión o contradicción en la exposición del fiscal; porque la sencillez está presente cuando el juez busca que se le conteste una pregunta de aclaración; en suma, la sencillez debe estar presente para convencer al juez de la existencia de un agraviado, porque hay un daño producto de un ilícito penal y se ha identificado al autor o partícipe del mismo, esto es, el agresor.

Pero, ¿cómo saber si estoy imputando correctamente el daño? Cuando del marco fáctico que el asesor está exponiendo en audiencia ante el juez, cuya explicación se desprende de las evidencias, se logre contestar, a saber, las siguientes preguntas:

- ¿Quién es el imputado? Labor de individualización tanto en la identidad como en el aporte fáctico, cuando hubiese más de un imputado.

- ¿Qué conducta realizó el imputado? Conociéndose las circunstancias de tiempo, modo y lugar.

- ¿La conducta es soportada por las evidencias?

- ¿La conducta se adecúa a un tipo penal? ¿Cuál tipo penal? Siendo claros en precisar que las figuras de cohecho en el Perú son dolosas, quedaría por contestar si el pragma típico está consumado o en grado de tentativa, con autor o con la presencia de partícipes, con atenuantes o agravantes o simplemente es el tipo base, en relación concursal con otros tipos penales, o es único el pragma típico que se maneja.

- ¿Quién es el agraviado? Si bien es el Estado, no existe impedimento alguno en especificar qué institución estatal ha sido afectada en el caso concreto.

- ¿El agraviado presenta daños tangibles? Si bien, doctrinalmente se agrupan tanto los daños físicos como materiales, no es usual que se presenten en la figura delictiva del cohecho, aunque de ser el caso de presentarse, deberá darse la explicación respectiva. 
- ¿El agraviado presenta daños intangibles? Así tenemos el caso del daño moral, presente en la afectación, por ejemplo, de la imagen y la buena reputación de la institución estatal.

- ¿Cuál es el daño emergente o lucro cesante que además presenta el agraviado? Tales figuras pueden surgir tanto en los daños tangibles como intangibles.

- ¿La tipología de daños que se maneja está soportada por las evidencias?

- ¿Existe una relación de causalidad entre la conducta ilícita del imputado con los daños? Explicación que también puede darse con las reglas de imputación objetiva.

- ¿Cuál es el factor de atribución? En materia penal, la responsabilidad es subjetiva, porque los factores de atribución que en este caso exige el derecho de daños es el dolo o la negligencia, categorías que a su vez exige la ley penal para clasificar los tipos penales, pero que, en el caso del cohecho, se adelantó que son de naturaleza dolosos.

Estos interrogantes no los hemos formulado de la nada, sino que han sido tomados de los elementos clásicos que devienen en la responsabilidad por los daños cometidos, esto es conducta ilícita, daño, nexo causal y factor de atribución, y que son de interés de la Procuraduría, al tener la expectativa de exigir la reparación civil.

No obstante, debemos enfatizar en que la imputación del daño es el discurso que debe tener presente el procurador ante cualquier audiencia que le sea notificada por el Órgano Jurisdiccional. En efecto, piénsese que se están solicitando providencias precautorias, pues cómo el procurador lograría un embargo precautorio si no puede explicarle al juez los datos fácticos evidenciados que sustenten una relación de causalidad entre la conducta ilícita del imputado, su actuar doloso y los daños al Estado. Asimismo, el citado discurso debe estar presente para convencer al juzgador lo equivocado del fiscal en abstenerse de investigar, en aplicar un criterio de oportunidad, en disponer el archivo temporal o el no ejercicio de la acción penal, para dejar sin efecto la disposición fiscal agraviante.

Asimismo, la imputación del daño es flexible, porque la propia teoría del caso del procurador es flexible. Por ejemplo, piénsese que durante la etapa intermedia, o bien durante la audiencia de juicio oral, el Estado agraviado viene sufriendo un daño emergente mayor a lo identificado y cuantificado en la investigación, entonces el procurador puede alegarlo como hecho superveniente, ofreciendo el material probatorio correspondiente, de conformidad con el artículo 373, numeral 1, del CPP. 
En suma, la herramienta epistémica del procurador es la imputación del daño; ello implica el conocimiento de los hechos, el acceso a las evidencias y el aporte del material probatorio, como el peritaje de evaluación de daños; además, conlleva que el procurador prepare sus argumentos con las teorías necesarias para el cometido: teoría del delito, teoría del proceso, teoría de los derechos humanos, como ejemplos. Sin embargo, no se ignoran los grandes enemigos para la justicia: la sobrecarga procesal que lleva a la explotación humana y, por ende, al descuido en la preparación de los casos para el procurador; el aprovechamiento económico indebido materializado en la corrupción de aquellos servidores públicos encargados, por un lado, en la investigación de los delitos y, por otro, en la administración de justicia; la ignorancia de nuestra sociedad, que nos polariza en violentos - por el sentimiento de no alcanzar justicia - o en resignados - moralmente disminuidos, despojados de nuestra racionalidad que nos animaliza-. Ojalá se dé la sana reflexión en torno a estos tópicos; si vamos a "humanizar" el proceso penal, que no sea a través del llanto, sino mediante la "función de la palabra": el abstraer y el hablar —el uso del lenguaje — es lo que nos denota como Homo sapiens.

\section{Elementos de la imputación del daño}

\section{La ilicitud penal de la conducta}

Alterini, Ameal y López (1995, p. 150) precisan que en el moderno derecho de daños se pone la mirada en la protección de la víctima, reformulando los presupuestos de aquella institución; aunque también debe afirmarse que el tránsito de la teoría del acto ilícito a la teoría del daño, en materia civil, ya se venía discutiendo desde la segunda mitad del siglo pasado (Cupis, 1975, p. 579 y López, 1964, p. 59; 1978, p. 11). En este sentido, las tendencias modernas postulan una reelaboración del fenómeno resarcitorio a partir de la prescindencia de la ilicitud, centrando toda la teoría sobre una nueva estructura, más funcional y dúctil a la hora de brindar una respuesta al problema permanente del daño sufrido (Estrella, 2009, p. 33). Claro está, que tal idea es predicable en el ámbito civil, pero no en el penal; en efecto, si el hecho no constituye delito, por haberse actualizado una causal de atipicidad, de justificación o de inculpabilidad, entonces el imputado no será responsable ni del delito ni de la reparación civil. Por tanto, la ilicitud penal de la conducta es el fundamento del deber de reparar el daño en el proceso penal. 
Ahora bien, por ilicitud penal de la conducta entendemos que el comportamiento atribuido al imputado debe ser típico, antijurídico y culpable; es decir, no basta predicar la antijuridicidad del accionar del procesado, sino que se debe demostrar que es un sujeto con capacidad de culpabilidad y, por ende, con capacidad para responder penalmente por su actuar. En ese orden de ideas, la base de la ilicitud es la conducta humana, esto es, que la acción humana modifique una parcela de la realidad. Y en esa línea, como la dogmática penal hace descansar la acción en la voluntad, su ausencia, en los casos de fuerza física irresistible, movimientos reflejos y estados de inconsciencia, llevará a la exclusión del delito por falta de su objeto de valoración.

En clave procesal, la conducta humana implica la explicación de las circunstancias de tiempo, modo y lugar que se le atribuye a una o varias personas. Así, la facticidad dota de sentido a la imputación del ilícito penal y a la imputación del daño, por lo que su exposición no debe limitarse a cómo se afectó el bien jurídico penalmente protegido, sino que se extiende a las consecuencias ulteriores al mismo: daño físico, daño material, daño moral, daño emergente o lucro cesante; siendo importante tanto el discurso del Ministerio Público así como el del procurador ante la autoridad.

Claro está que también la defensa tiene el derecho a emitir su discurso sobre la facticidad del caso; es decir, aquellas circunstancias de tiempo, modo y lugar que constituyen la base de su estrategia procesal, v. gr. el falseamiento de los datos por parte de los órganos públicos de investigación para efecto de "crear" a un delincuente, o bien el compartir o el disentir la base fáctica de imputación delictiva para el logro de una clasificación jurídica más favorable a los intereses del imputado - pensando en una terminación anticipada o en una conclusión anticipada-; pero también tendría que pensar en la facticidad de la imputación del daño, incluyendo las evidencias, para que la medida de reparación del daño que se fije sea equitativa y justa.

Por otro lado, las partes interesadas en la imputación delictiva, así como del daño, necesitan convencer al juez de que la conducta del procesado es típica; para ello, se deben respetar los principios de subsidiariedad y fragmentariedad, para luego, con la técnica legislativa adecuada, presentar a la ciudadanía la materia de prohibición, esperando que se motiven en la norma para efecto de una mejor protección de los bienes jurídicos protegidos, y para ello también se tendrán que respetar las exigencias del principio de legalidad. En efecto, el legislador selecciona aquellos comportamientos más disvaliosos para la convivencia pacífica en sociedad, incurriendo, en algunos casos, a su equiparación como violaciones a los derechos humanos; para 
luego presentar a la ciudadanía lo que está prohibido y por ende sancionado, esto es una conducta y en su caso un resultado, así como la presencia de un agresor y una víctima u ofendido, que en el caso del cohecho es el Estado; sujetos y acciones que representan el aspecto objetivo del tipo penal o los denominados elementos objetivos del tipo penal, porque son percibibles, facilitando la valoración por parte del operador.

Igualmente, el legislador atiende a los denominados hechos internos o psíquicos de la persona humana, entendiéndose los mismos como la orientación o el contenido de la voluntad, los cuales generan juicios de valor por parte del operador, quien puede entender que la persona ha adoptado una postura de querer afectar el bien jurídico protegido, legalmente conocido como dolo, o bien en su apresuramiento para el logro de la finalidad que le hizo incurrir a la persona en un yerro, descuido o imprudencia; así, dolo o culpa son considerados como los elementos subjetivos del tipo penal, pero en el cohecho el factor de atribución es el dolo.

Además, el operador debe tomar en cuenta que el objeto de la prohibición legislativa puede presentar elementos con significación normativa propia; es decir, conceptos que han surgido del lenguaje jurídico, v. gr. bien mueble, o bien ante problemáticas como la polisemia o la pluriculturalidad, donde se elaboró una regla insertada en alguna norma legal que no se puede desatender, v. gr. el concepto de muerte, que surge de las normas legales de salud. Estos elementos presentes en el pragma (hecho) típico son identificados como elementos normativos del tipo penal.

Así, para que la conducta imputada sea típica deberá actualizar los elementos objetivos, subjetivos y normativos señalados en el tipo penal, para lo cual la doctrina ha sugerido la aplicación de las reglas tanto de la imputación objetiva como subjetiva. En el primer caso, la creación de un riesgo jurídicamente desaprobado que presenta una relación con el resultado acaecido, y que además se adecúa al fin de protección de la norma, son los argumentos que sustentan a la imputación objetiva, con la advertencia al lector de que la aplicación de estos criterios exige la elección de las por ahora directrices de imputación: porque la persona infringió su rol social o porque la persona tiene la capacidad de dominar su acción y por ende la virtualidad de afectar el bien jurídico protegido. Por otro lado, la imputación subjetiva denota que el dolo no se prueba si no se infiere de la acción del agresor, esto es, que conociendo lo que está inobservando continúa su accionar, afectando el bien jurídico protegido; en cambio, la imprudencia descansaría en una ceguera de los hechos, esto es, en el desconocimiento del carácter agresivo 
de la acción; asimismo, se debe tomar en cuenta el error de tipo a la hora de afirmar o descartar el aspecto subjetivo del tipo penal que se esté examinando, aunque, se insiste, la eliminación del dolo conllevaría la atipicidad de la conducta frente al cohecho.

Por otro lado, en el caso del cohecho, el bien jurídico es el correcto funcionamiento de la administración pública (Reyna, 2011, p. 119) o la integridad de la función pública (Mata, 2006, p. 81 y Valeije, 1996, p. 30). Asimismo, el carácter de injusto de la conducta se completa cuando se afirma la ausencia de causales que justifiquen el comportamiento agresivo al bien jurídico protegido. Para ello se debe aplicar el principio de ponderación cuando se analizan las figuras de legítima defensa, estado de necesidad justificante, consentimiento, ejercicio de un derecho o cumplimiento del deber, y de no operar ninguna se afirma el carácter antijurídico de la acción. Finalmente, una vez afirmada la antijuridicidad se pasa al juicio de culpabilidad, esto es, el examen de las circunstancias físicas, psicológicas, emocionales y culturales del sujeto, para efecto de establecer si presenta situación de normalidad para atender la exigencia de la norma y así reprocharle su actuar. Al superarse estos juicios de valoración, entonces se podrá afirmar la ilicitud de la conducta.

\section{El daño}

El daño es la afectación de un interés, la cual recae en un bien o beneficio que se destruye, deteriora, modifica o se vuelve inutilizable, incluyendo la pérdida de rentabilidad, extendiéndose además al sufrimiento y el dolor por la pérdida; así, con el citado concepto podemos abarcar tanto lo tangible como lo intangible. Como se aprecia, la definición esta signada al "interés", puesto que la doctrina no ha reparado en determinar un fundamento común entre las diversas clases de daños, por el contrario, han venido agregando y agregando más tipos de daños y, en vez de formular una base común, justifican sus apariciones con solo diferencias. No obstante, consideramos que sí es posible elaborar un fundamento o base, el cual es el "interés". Esto quiere decir, que ya sea daño moral, fisiológico, patrimonial, ambiental, etc., todos responden al menoscabo de un interés de la o las víctimas u ofendidos.

Sin embargo, la exposición no solo concluye con esta teoría del "interés", sino que permitirá resaltar el aspecto económico-funcional de los daños. Es económico, porque la consecuencia jurídica de la responsabilidad del daño derivada de la comisión de un delito es la indemnización, siendo su manifestación por excelencia la reparación por equivalencia dineraria (la 
otra manifestación es la reparación in natura), aunque no es la única - y el plexo de posibilidades ha sido establecido, por ejemplo, por la jurisprudencia de la Corte Interamericana de Derechos Humanos, como vendría a ser el caso de las disculpas públicas-. Siendo que la determinación indemnizatoria de daños y perjuicios debe ser en función del contenido económico que, en equivalencia, es lo que ha sufrido la víctima u ofendido de los daños a consecuencia de la comisión de un ilícito penal.

Así, nuestro concepto es funcional, porque un concepto de daños que gire en torno al menoscabo del interés de la víctima u ofendido del delito permitirá que el sistema de responsabilidad civil o del daño sea eficaz y cumpla con sus funciones y fines. En efecto, este sistema, aparte de buscar internalizar las externalidades, persigue la distribución del riesgo y la reparación equitativa y eficaz a la víctima (u ofendido) de las externalidades; para ello, la víctima u ofendido por la comisión de un injusto penal reprochable debe dar por cierto y probado la presencia de una afectación.

Por otro lado, no se ignora que, en las decisiones judiciales, así como en la literatura jurídica, se ha hecho referencia a diversos tipos de daños, por ejemplo: daño físico, daño estético, daño a la salud, daño mental, daño emocional, daños materiales, daño a la propiedad privada, daño a la propiedad pública, daño al patrimonio histórico, cultural o artístico, daño ambiental, daño emergente, lucro cesante, entre otras figuras. En ese sentido, no pretendemos añadir más expresiones que puedan causar confusión, pero sî partimos de que los daños, cualquiera que fuesen, pueden ser cuantificados económicamente a través del peritaje de evaluación de daños, entonces necesitamos recurrir a la disciplina o a la técnica que la sustenta para una adecuada clasificación de los daños. Así, en economía, finanzas y contabilidad, valuar implica fijar el precio o valor de algo; si bien, su ámbito de aplicación ha sido el empresarial, la metodología de evaluación, tanto de activos tangibles e intangibles, presenta la cientificidad necesaria para ser tomada en cuenta por el operador a la hora de fijar el monto de la indemnización; en efecto, si partimos de un modelo de multicriterios como el proceso jerárquico analítico de Saaty, se podrá organizar la información obtenida - así sea cualitativamente - para efecto de valuar el daño que los referidos activos han sufrido.

En ese contexto, podemos identificar dos categorías: daños tangibles y daños intangibles. A continuación, desarrollaremos la citada taxonomía. En esa inteligencia, por daños tangibles entendemos a la pérdida, la destrucción o la modificación en lo referente al cuerpo humano, incluyéndose 
los componentes de estructura y funcionamiento del medioambiente, a lo que también se integra la biodiversidad, así como a los objetos o cosas que conforman el patrimonio de la persona humana o moral o bien del disfrute colectivo. En cambio, los daños intangibles operan en la afectación al capital intelectual de la persona humana, a sus derechos de personalidad como la imagen y la buena reputación, así como a su esfera afectiva o emocional. Por otro lado, tanto los daños tangibles como intangibles, a su vez, pueden generar más perjuicios para el afectado, los cuales han sido clasificados en daño emergente y lucro cesante. Así, el daño emergente, en una fórmula muy simple, lo conforman las sumas de dinero que salen del patrimonio del perjudicado para atender las consecuencias del daño. Esta pérdida puede presentarse como consecuencia directa y súbita del daño; hay otras que se manifiestan posteriormente, las cuales se pueden prever desde ahora, y otras que ni siquiera se sospechan al momento del accidente (daños futuros).

Finalmente, el lucro cesante es la pérdida de ganancia, de beneficio y utilidad que sufre el perjudicado como consecuencia del hecho dañoso. Asimismo, la exigencia probatoria del lucro cesante será inversamente proporcional al juicio de probabilidad; en otros términos, cuanto mayor sea la probabilidad de que el lucro cesante se hubiera obtenido, menor será la exigencia en la prueba del mismo, y, al contrario, cuanto menor sea la probabilidad de obtención del lucro cesante, mayor será su exigencia probatoria.

\section{La relación de causalidad/imputación objetiva}

En los dos últimos siglos, se ha señalado que la causalidad está en crisis. Así, Russell, a comienzos de la segunda década del siglo XX, comentó que la causalidad no era útil para las ciencias avanzadas (Bárcena, 2012, p. 5) y, en la actualidad, por la presencia del normativismo en el pensamiento jurídico-penal, es una figura que ha quedado relegada por la teoría de la imputación objetiva (Rueda, 2011, p. 282).

Nosotros hemos postulado la importancia de la facticidad, esto es, de la explicación de los hechos para conocer el caso; en esa inteligencia, sea un análisis de causalidad o de imputación objetiva, se debe establecer una relación entre la ilicitud de la conducta con el daño a la víctima u ofendido. En ese sentido, para poder imputar objetivamente a una persona un resultado este debe poder explicarse mediante un comportamiento prohibido. Lo que quiere decir que de entre las condiciones de producción del resultado el derecho penal considera como factor determinante el comportamiento prohibi- 
do del autor. No se trata, por tanto, de describir una vinculación causal entre el comportamiento y el resultado, sino de un juicio de valoración normativa: atribuir el resultado dañoso a "mi" actuar; algo, por otra parte, especialmente difícil en los delitos de omisión y en ámbitos complejos como el medioambiente o la responsabilidad por el producto. Ahora bien, desarrollar la teoría de la imputación objetiva excedería la finalidad del presente estudio.

\section{El factor de atribución}

En materia de responsabilidad extracontractual se identifican dos sistemas de atribución: el objetivo y el subjetivo. Así, la responsabilidad será subjetiva si se funda exclusivamente en el dolo o la culpa del agente; y será objetiva cuando se produce con independencia de toda imputación subjetiva; de manera que, en el primer caso, el sujeto activo realiza un hecho ilícito que causa un daño al sujeto pasivo, y en el segundo, obra lícitamente pero el daño se produce por el ejercicio de una actividad peligrosa o por el empleo de cosas peligrosas, razón por la cual también se conoce a la responsabilidad objetiva como responsabilidad por el riesgo creado.

Doctrinalmente, se considera que un sistema fundado en el dolo o la culpa delimita un radio de actividades de las que el potencial autor del daño debe hacerse cargo, reservando un ámbito en el que la propia víctima debe asumir su propio cuidado. En cambio, en el sistema de responsabilidad objetiva, el mismo se justifica en la medida en que la actividad supone un riesgo intrínseco, o las medidas de cuidado que la propia víctima puede adoptar resultan superfluas (Aedo, 2014, p. 23). Ahora bien, resulta relevante analizar si la reparación civil derivada de la comisión del delito de cohecho puede descansar en los factores de atribución objetiva y subjetiva, o bien solamente en una de ellas, lo que ocuparía definir la "culpa civil". Frente a ello, el factor de atribución invocable en sede penal es el subjetivo, por lo que se reitera la inquietud de si la culpa civil se equipara a la culpa penal. No obstante, se debe indicar que este tópico ha sido estudiado desde antaño (Castejón, 1948, p. 477 y Quintano, 1957, p. 1039), siendo llamativo que la doctrina civilista afirme que la culpa ha pasado de una concepción psicológica a una normativa, la cual, y citando a Fernández (2005), consiste en lo siguiente: "hoy el término culpa expresa simplemente la falta de adopción de las medidas de precaución debidas, sobre la base de los conocimientos posibles de una persona-tipo" (p. 244). 
$\mathrm{Al}$ respecto, el mencionado concepto de culpa civil se asemeja a los elementos subjetivos del tipo penal y, por ende, del injusto. En efecto, la ilicitud de la conducta, que tanto el artículo 1969 del Código Civil peruano así como el artículo vir del Título Preliminar del Código Penal peruano y los artículos 11 y 12 de la norma legal citada, se exige que el actuar sea doloso o imprudente por parte del agente; y claro, en ambos casos se actúa infringiendo el deber de cuidado, de diligencia o de precaución, solo que, en el caso del dolo, el agente se comporta con el conocimiento de esa infracción y que va a afectar el bien jurídico protegido; en cambio, en la imprudencia, el agente actúa con ceguera de los hechos, aunque por sus condiciones personales le era previsible conocer. En efecto, para Zaffaroni (2007): "El dolo es definido como la voluntad realizadora del tipo guiada por el conocimiento de los elementos objetivos del tipo, siendo este último siempre efectivo" (p. 403). Asimismo, entre las clases de dolo tenemos: el dolo de primer grado, el cual también abarca el segundo grado, pero este último no al primero. En este sentido, el dolo de "consecuencias necesarias" se presenta cuando se prevé el resultado y es asumido por el realizador de la acción (el ejemplo clásico es el terrorista que, con el fin de asesinar al embajador, coloca una bomba en el auto diplomático, dando por sentado que además del político le dará muerte al conductor del vehículo). Así ha resuelto, en numerosas ocasiones, la jurisprudencia alemana diciendo que las consecuencias de la acción que se reconocen como necesarias son asumidas en su voluntad por el agente, aun cuando no tenga en absoluto interés en esas consecuencias (Pérez, 2017, p. 217). Igualmente, se tiene la figura del dolo eventual, la cual no es ajena a la concepción cognitiva del dolo, esto es, que existe certeza de la realización de la conducta típica y, sin embargo, continúa con su accionar, resignándose a la eventual realización del delito.

Por su parte, la imprudencia, como infracción al deber objetivo de cuidado, nace en la equivocada selección de los medios para lograr la finalidad formulada por el sujeto activo. Ahora bien, no se ignora que es la culpa sin representación la figura paradigmática, dado que el agente, a pesar de poseer los medios para representarse el peligro de su accionar, no lo hace; en cambio, en la culpa con representación, si bien se conoce el riesgo de la conducta, se confía en que el resultado típico no sucederá. Sobre esta última figura aún se aprecia ceguera en los hechos, esto es, la equivocada representación de la peligrosidad del medio elegido, en cuanto al control del resultado, por lo que se puede identificar la diferencia con el dolo. Entonces, como se ha indicado en repetidas oportunidades, las figuras de cohecho son 
dolosas y, por ende, la imputación subjetiva se limita al dolo y a aquellos elementos subjetivos distintos al dolo que la ley penal así exija. No obstante, la imputación subjetiva implica asumir una concepción del dolo. Así, históricamente, el sistema judicial peruano ha exigido que el agente haya realizado un juicio del peligro que su actuar puede generar, y por indiferencia o por objetivo asumido, continúa con su actuar. Esta fórmula es la exigencia del cruce entre el conocer — juicio de peligro- y la voluntad — directa o indiferente - .

Claro está que la citada fórmula incrementa el estándar de prueba, aumentando el espectro de absoluciones por insuficiencia probatoria. Frente a ello, se torna mayoritaria la posición de que el dolo es conocer, esto es, que por las singularidades que presenta el caso concreto es lógico inferir que el sujeto activo conocía de lo peligroso de su actuar. V. gr., si el funcionario público se reúne en un restaurante con el administrador, quien le explica el acto de autoridad que necesita, recibiendo de este último un sobre de dinero, es evidente que los actores de este evento están actuando con conocimiento del actuar y de sus singularidades antinormativas, por lo que puede justificarse la imputación subjetiva del dolo del cohecho, no siendo necesario probar o inferir la voluntad dolosa. Sin embargo, no se desconoce la denominada teoría de la ignorancia deliberada, de origen anglosajón, en donde se postula que no se debe eximir a aquel sujeto activo que decidió no realizar ningún juicio de peligro con relación a su entorno. V.gr., el gerente que les dice a sus empleados que no le interesa el cómo, ni desea saberlo, pero deben de lograr el " $\mathrm{x}$ " acto de autoridad; como se aprecia, el ignorar una determinada cadena de sucesos implica no tener el suficiente conocimiento de algo y, por ende, no estaría dicha persona en actitud de realizar el juicio de peligrosidad, por lo que, aun el imputarle el dolo implicaría asumir un dolo sin conocimiento; no obstante, para evitar zonas de impunidad, la imputación subjetiva se justificaría, sea por la regla de la indiferencia del dolo eventual o bien invocar la teoría en cuestión al afirmar que habiendo una sospecha previa de la legalidad del acto de autoridad, existe una persistencia en el ignorar por parte del sujeto activo, lo cual le ha traído beneficios personales sin asunción de riesgos (Ragués, 2013, p. 11).

Por otro lado, para efecto de cuantificar el monto de la compensación, el artículo 93 del Código Penal peruano no menciona el dolo o la culpa como criterios sustentadores o diferenciadores, y ello debe ser entendido a través de una interpretación sistemática con el artículo 1969 del Código Civil peruano, que señala que el dolo o la culpa son factores de atribución 
de responsabilidad, pero no para fijar el monto de la indemnización. Frente a ello, si el factor de atribución no influye en el monto indemnizatorio, entonces por qué mencionarlo. Bueno, en principio el daño tangible e intangible es consecuencia de la ilicitud de la conducta, sea dolosa o culposa, y no es que la vida humana privada tenga mayor valor si la conducta antijurídica fue con dolo y de menor valor si fue con culpa; al contrario, las consecuencias nacidas de la acción de matar deberán ser reparadas a favor de los ofendidos, de manera integral y justa. En esa línea, la importancia del factor de atribución gira en torno a ser elemento del injusto penal, y este último constituye presupuesto, junto con la culpabilidad, para la reparación del daño; sin una imputación subjetiva de la conducta al sujeto activo, entonces no se puede afirmar que se comportó ilícitamente, por lo que su actuar no es un criterio de explicación de la afectación al bien jurídico y de los daños que han surgido. Por tanto, al ser presupuesto, la imputación subjetiva del dolo o la culpa debe ser un tema central en el discurso del Ministerio Público, así como del procurador, pero también de la defensa, en clave de postular su ausencia o defender una imputación subjetiva más benigna para su prohijado.

\section{Peritaje de evaluación de daños en el delito de corrupción de funcionarios}

En un reportaje periodístico, se indicó que la empresa brasileña Odebrecht, involucrada en procesos penales anticorrupción, tendrá que pagar seiscientos diez millones de soles - el equivalente a doscientos millones de dólares americanos- por concepto de reparación civil. En esa inteligencia, la pregunta gira alrededor de conocer el fundamento o las razones que justifican el monto antes mencionado; es decir, al menos se levantan dos arenas de discusión: si en los delitos de mera actividad como el cohecho se puede hablar de reparación civil y cuáles son los conceptos legalmente indemnizables que surgen de la comisión del delito en cuestión.

Con relación al primer punto, tenemos una posición oficial, el Acuerdo Plenario 6-2006, en donde la Corte Suprema se pronuncia sobre la reparación civil en los delitos de peligro, indicando en el fundamento décimo lo siguiente: 
10. A partir de lo expuesto, cabe establecer si los delitos de peligro pueden ocasionar daños civiles y, por tanto, si es menester fijar la correspondiente reparación civil, más allá de las especiales dificultades que en estos delitos genera la concreción de la responsabilidad civil.

Como se ha dicho, el daño civil lesiona derechos de naturaleza económica y derechos o legítimos intereses existenciales, no patrimoniales, de las personas. Por consiguiente, aun cuando es distinto el objeto sobre el que recae la lesión en la ofensa penal y en el daño civil, es claro que, pese a que no se haya producido un resultado delictivo concreto, es posible que existan daños civiles que deban ser reparados. En los delitos de peligro, desde luego, no cabe negar a priori la posibilidad de que surja responsabilidad civil, puesto que en ellos -sin perjuicio, según los casos, de efectivos daños generados en intereses individuales concretos- se produce una alteración del ordenamiento jurídico con entidad suficiente, según los casos, para ocasionar daños civiles, sobre el que obviamente incide el interés tutelado por la norma penal -que, por lo general y que siempre sea así, es de carácter supraindividual. Esta delictiva alteración o perturbación del ordenamiento jurídico se debe procurar restablecer, así como los efectos que directa o causalmente ha ocasionado su comisión [el daño como consecuencia directa y necesaria del hecho delictivo] (conforme: Roig Torres, Margarita: La reparación del daño causado por el delito, Editorial Tirant lo Blanch, Valencia, 2000, páginas 124-125). Por consiguiente, no cabe descartar la existencia de responsabilidad civil en esta clase de delitos, y, en tal virtud, corresponderá al órgano jurisdiccional en lo penal determinar su presencia y fijar su cuantía.

\section{siguiente:}

Al respecto, ha sido crítica Villanueva (2017), quien ha señalado lo

en los delitos de peligro abstracto no es posible pronunciarse sobre la reparación civil, toda vez que no hay daño civil que reparar. No es controvertible que en determinados delitos de tentativa o de peligro concreto sea posible verificar aunque sea un daño moral a la víctima — dado el impacto emocional que la acción del delincuente despliega contra la víctima-, por lo cual asumimos que los magistrados, en esos casos, no tendrían la necesidad de entrar a cuestionarse sobre el nuevo daño civil producido por la alteración del orden jurídico (p. 65). 
En esa inteligencia, aun si se identifican conductas antinormativas calificadas como delitos de mera actividad, así como de peligro (Rodríguez, 2012, p. 57), y con ello el fundamento de la afectación al ordenamiento jurídico, no se contestaría a la interrogante de cómo cuantificar el monto de la indemnización por reparación civil, máxime que, si se contesta que el ordenamiento jurídico es incuantificable, entonces quedaría la cuantificación en la libre discreción del operador, surgiendo otras clases de problemas relacionados con la motivación de las decisiones judiciales.

Por otro lado, este tema no ha sido ignorado en la jurisprudencia comparada; en ese sentido, María Acale (2002) señala las siguientes sentencias españolas:

La sTs de 15 de abril de 1991 entiende que "la responsabilidad civil derivada de un hecho ilícito exige, como elemento estructural de la misma, una relación de causalidad entre la acción u omisión delictiva y el daño o perjuicio sobrevenidos - vid sentencias de 10 de febrero de 1955 y de 4 de noviembre de 1981-. Las únicas infracciones penales susceptibles de engendrar responsabilidad civil son aquellas en las que el hecho, además de ser constitutivo de delito, por venir tipificado como tal en el Código Penal, constituye, a la vez, un ilícito civil, generador de un daño de esta naturaleza, a cuyo resarcimiento se encamina la acción civil correspondiente; por lo cual, algunos mantienen la opinión de que los delitos formales o de peligro no son susceptibles de generar responsabilidad civil (sentencia de 4 de noviembre de 1981)". También niega la responsabilidad civil en los delitos de mera actividad la Sentencia de la Audiencia Provincial de Málaga de 10 de octubre de 2000, en la que se liquidan responsabilidades penales en el conocido "asunto de las camisetas" que sentó en el banquillo de los acusados al alcalde de Marbella y presidente de la entidad deportiva Atlético de Madrid. En la misma se establece: "en orden a la responsabilidad civil 'ex delicto'... hemos de manifestar que no cabe establecer reparación económica de condena por delitos que no producen lesión de esta índole, pues ya se dijo que la prevaricación es un delito de mera actividad y no de resultado lesivo, y si en algún sentido cabe así considerarle es por la lesión que produzca a la Función Pública, bien jurídico de naturaleza ideal que no se corporiza en nada, matizándose que el tipo del delito de tráfico de influencias alude a la obtención de un beneficio económico (no habla de ilícito) que la Sala estima que no ha quedado precisamente acreditado, pues las cantidades pagadas obedecen a una prestación efectivamente rea- 
lizada, reservándose a la Vía de la Jurisdicción Administrativa u otra que proceda, la posibilidad de pronunciarse en su caso, sobre esta cuestión si procede y sobre la validez o nulidad de las contrataciones efectuadas" (p. 39).

Sin embargo, se han hecho formulaciones teóricas para justificar la reparación civil en los delitos de mera actividad y, por ende, de cohecho; así, la propia Acale (2002) ha indicado lo siguiente:

En este sentido, también los delitos de mera actividad pueden dar lugar a responsabilidad civil, no solo por daños morales, sino también por daños materiales, en la medida en que el artículo 109.1 está refiriéndose al daño al bien jurídico. Ahora bien, dicho daño no ha de entenderse tampoco como "lesión" al bien jurídico, lo que supondría negar la responsabilidad civil en aquellos supuestos en los que no se constatara esa forma de afección al interés protegido. Por el contrario, también los delitos de peligro o la tentativa de delito pueden dar lugar a la responsabilidad criminal si de la puesta en peligro se han deducido daños morales o materiales resarcibles económicamente. Por todo ello, es preferible no hacer afirmaciones categóricas, en la medida en que como afirma Córdoba Roda, resulta incorrecto afirmar que en ningún caso estos delitos puedan dar lugar a responsabilidad civil (p. 40).

Frente a ello, nuestra posición gira en torno a no reducir el argumento a la afectación del ordenamiento jurídico, en razón que no es un concepto legalmente indemnizable; en efecto, el artículo 101 del Código Penal peruano nos remite al Código Civil para la determinación de la indemnización; en esa inteligencia, el artículo 1985 de la norma civilista ha establecido lo siguiente:

La indemnización comprende las consecuencias que deriven de la acción u omisión generadora del daño, incluyendo el lucro cesante, el daño a la persona y el daño moral, debiendo existir una relación de causalidad adecuada entre el hecho y el daño producido. El monto de la indemnización devenga intereses legales desde la fecha en que se produjo el daño. 
La norma citada ha enumerado los conceptos indemnizables, en donde no se indica la afectación al ordenamiento jurídico, sino la existencia de un daño, el cual, como se indicó en los apartados anteriores, puede ser tangible, como el daño físico o el material, así como intangible, como el daño moral; a ello, la norma en cita agrega el lucro cesante, pero también menciona una figura muy discutida en nuestra doctrina, como es el daño a la persona (Leysser, 2020, p. 11).

Desde el Código Civil peruano, el procurador o abogado del Estado tendrá que probar que el acto corrupto ha generado para el Estado peruano consecuencias dañosas para sus intereses; por ejemplo, piénsese que mediante un soborno la empresa $\mathrm{x}$ logró que la inspección en la construcción del hospital y - ahora con el tema del coronavirus - le sea favorable; sin embargo, terminada la construcción, y en atención a una denuncia por el delito de cohecho, una segunda inspección revela que se está ante una obra de mala calidad, que no ha cumplido con los estándares requeridos para la construcción de hospitales. Al respecto, el procurador, desde la imputación del daño, tendrá que explicar y acreditar los daños que le han surgido al interés estatal, por no descartar el interés público; por ejemplo, daños materiales, incluyendo el emergente, destinado a recuperar la obra pública. Igualmente, se puede hablar de daños materiales, daño emergente y lucro cesante cuando hablamos de sobornos para encubrir carreteras y casetas de cobro de peajes mal hechas. Hoy en día, no podemos ignorar el criterio de confiabilidad de un determinado país frente a la comunidad internacional, que se mide de diferentes maneras, entre ellas el ranking referido a la corrupción; por esta razón, las figuras de cohecho también tienen la potencia de generar un daño moral, de carácter objetivo o de imagen, a las instituciones públicas peruanas.

Por tanto, no se requiere recurrir al artilugio de la afectación al ordenamiento jurídico para justificar la reparación civil cuando, y según la singularidad del caso concreto, se pueda acreditar la existencia de consecuencias dañosas para el Estado por parte del acto corruptor - así sea un delito de mera actividad-, y para ello, la prueba pericial se levanta como una necesidad epistémica.

Por otro lado, tenemos que diferenciar la prueba del daño de la prueba de la cuantificación de la indemnización, dado que ambas responden a métodos diferentes. Para probar el daño se debe partir de la naturaleza y los alcances de la conducta ilícita; así, si el acto corruptor ha girado en torno a obras públicas, la pericia de ingeniería civil sería idónea para la determinación de daños materiales, así como la pericia contable sería útil para acreditar el lucro cesante; en cambio, si el acto corruptor gira acerca de 
los servicios públicos, la prueba documental referida tanto a la existencia del soborno o del acto de autoridad nacido del acto corruptor, así como el referido a la medición del combate a la corrupción, como sería el caso de los ranking, justifican la mención de un daño moral objetivo, sin perjuicio del peritaje de contabilidad para el ítem del lucro cesante. Asimismo, la determinación del quantum indemnizatorio partirá de la revisión de una serie de factores que deben estudiarse a partir de un método concentrado en los derechos o intereses transgredidos y sus consecuencias, recordando que la noción de montos fijos o de límites mínimos y máximos que impidan la individualización de las medidas reparadoras es contraria a la idea que persigue el concepto de justa indemnización. Este método es el que deberá trabajar y explicar el perito evaluador de daños.

En efecto, la valuación es la acción o efecto de valuar, a su vez, significa valorar, entendido como el reconocimiento o apreciación del valor de algo. Es un término utilizado en similitud retórica con tasación y valoración. La Real Academia de la Lengua Española (RAE) la define como la acción y el efecto de valorar, y valorar es reconocer, estimar o apreciar el valor o mérito de alguien o algo. Respecto a la palabra tasación, la RAE la define como la estimación del valor de un bien o de un servicio. En este sentido, la tríada de términos guarda una estrecha vinculación entre sí, donde el punto de similitud es la referencia al concepto valor, determinado mediante un avalúo (Salas, 2015, p. 4).

Ahora bien, para Aznar y Guijarro (2012), quienes emplean la palabra valoración como equivalente a valuación:

Las dos premisas básicas sobre las que se sustentan los métodos modernos de valoración son: el carácter finalista de cualquier proceso valorativo y la unicidad de métodos. La primera premisa implica, que según sea el fin por el que nos proponemos valorar un determinado bien, así será el criterio de valoración que debamos aplicar. La segunda premisa implica una generalización aplicativa de los métodos de valoración, independientemente del tipo de bien que estemos valorando. Es decir, existe una teoría de valoración, que como toda teoría científica se encuentra en un continuo proceso de mejora (la metáfora popperiana de la "búsqueda sin término"), pero que su aplicabilidad se extiende a cualquier tipo de bien. Dicho con otras palabras, la unicidad de métodos implica que desde un punto de vista epistemológico no tiene sentido hablar de una teoría de la valoración de inmuebles, de una teoría de la valoración agraria, etc., sino de una teoría general de la valoración (p. 9). 
En esa línea, esos mismos autores proponen la siguiente definición:

La valoración es la ciencia aplicada que tiene como objetivo la determinación del valor de un bien, teniendo en cuenta los elementos de comparación, características o variables explicativas que lo caracterizan, el entorno económico-temporal en que se encuentra, mediante la utilización de un método contrastado de cálculo aplicado por un tasador profesional, y que permita al experto incorporar tanto el conocimiento objetivo y las variables cuantitativas, como el conocimiento subjetivo y las variables cualitativas (Aznar y Guijarro, 2012, p. 19).

Ahora bien, vamos a emplear la expresión "evaluación económica de los daños" en un sentido amplio, que comprende todos los conceptos indemnizables establecidos en la ley; y para el logro de la evaluación se requiere utilizar la teoría de la decisión multicriterio, esto es, para establecer el monto de la compensación económica —elegir el quantum indemnizatorio- el tasador tendrá que trabajar una serie de alternativas, predeterminadas en la norma legal, y a su vez un conjunto de criterios que dote de sentido económico a las referidas alternativas; por lo que, el primer paso en un proceso de toma de decisiones es definir los criterios que nos ayudarán a decidir y a fijar un valor económico a cada uno de los conceptos legalmente indemnizables, y una vez definidos es lógico pensar que todos no tienen por qué tener la misma importancia, por lo que el siguiente paso será ponderarlos (determinar el peso o la importancia).

En esa inteligencia, se cuenta con el proceso analítico jerárquico, el cual parte del interés que puede tener un decisor en seleccionar la más interesante, entre un conjunto de alternativas, para luego definir los criterios que se van a utilizar para determinar la selección, esto es, cuáles son las características que pueden hacer más deseable una alternativa sobre otra. Conocidas las alternativas y definidos los criterios, debe primero procederse a ordenar y ponderar el diferente interés de cado uno en la selección de las alternativas. El procedimiento seguido es la comparación por partes cuantificadas mediante una escala.

Conocida la ponderación de los criterios se pasa a ponderar las distintas alternativas en función de cada criterio. Para ello se comparan todas las alternativas en función de cada criterio, y obtendremos $n$ matrices, siendo $n$ el número de criterios; de cada una de ellas se calcula su vector propio, que en cada caso nos indicará la ponderación de las distintas alternativas en función de cada criterio. 
Con los dos procesos anteriores se obtienen dos matrices, una con la ponderación de criterios y otra con las ponderaciones de las alternativas para cada criterio. El producto de la segunda matriz por la primera dará una matriz que indica la ponderación de las alternativas en función de todos los criterios y del peso o importancia de estos, y que por lo tanto nos indica cuál alternativa es la más interesante. El resultado final en aplicar este método es la obtención de un vector que nos señala la ponderación o peso de cada una de las alternativas en función de todos los criterios y su importancia; esta particularidad es la que nos va a permitir su aplicación en valuación. Ahora bien, y antes de empezar a desarrollar la temática de la evaluación de los daños en el cohecho, se debe precisar lo siguiente: 1) el valuador tomará las circunstancias del caso concreto; en efecto, si bien hay normas que reglamentan determinadas áreas de la valuación (v. gr. inmuebles de propiedad pública), también es cierto que se toma en cuenta las particularidades de cada caso, y 2) el valuador trabajará con información cuantitativa y cualitativa, fruto de haber aplicado diferentes técnicas e instrumentos de recolección de datos, como vendría a ser el caso de la encuesta, la cual aplica una vez delimitada su población y muestra, y cuyos datos obtenidos procesará, ya sea con la escala de Likert o mediante la prueba de chi cuadrado o cualquier otro paquete estadístico de su predilección.

En esa inteligencia, piénsese en los daños materiales relacionados a sobornos en obras públicas; para aplicar el proceso analítico jerárquico se debe plantear el problema, que seguro es la determinación del monto de la compensación por los daños sufridos al inmueble de x, para luego continuar con la propuesta de Aznar y Guijarro (2012, pp. 143-149) de cuatro niveles, los cuales son:

- Nivel 1: es el objetivo o meta. Calcular la compensación económica por los daños sufridos en el inmueble de $\mathrm{X}$.

- Nivel 2: recoge las metavariables, las variables explicativas generales o las primarias.

- Nivel 3: compuesto por las variables explicativas secundarias o subvariables.

- Nivel 4: recoge las obras públicas comparables y la obra pública que se debe valorar de $\mathrm{x}$. 
Ahora bien, el producto obtenido es solamente la compensación que el Estado debería recibir por el daño emergente, en el entendido de que si quiere trabajar sobre su inmueble recuperaría su valor en comparación con las demás obras públicas del sector.

Por otro lado, está la evaluación del daño moral, que para el caso que nos ocupa surge cuando el cohecho ha afectado la imagen estatal, conocida como la marca pública. En efecto, y siguiendo a Jordi de San Eugenio, la marca no solo se constituye hoy a modo de importante activo del territorio, en la tarea de contribución a la fijación de una identidad y de una reputación, sino que se vislumbra la llegada de una estrategia que dota de nuevas oportunidades a los territorios, en el sentido de ofrecerles nuevas vías de desarrollo a partir de la captación de inversiones, talento, infraestructuras, etc. La marca de territorio tiene asignados diferentes roles en función de la escala geográfica en la que se encuentra circunscrita. Se constata que las marcas de naciones y países se refieren a algo más sobrio, más representativo, con una vocación claramente institucional y, por tanto, con una incidencia relevante de tipo estructural en la imagen de una entidad territorial nacional. En el ámbito específico de los países y las naciones, se produce una clara evolución de la variable identidad en los últimos años, que parte de una situación inicial de identidad nacional, seguida por la importancia de fijación de una identidad territorial, para, actualmente, trabajar de manera específica con lo que se conoce como identidad de marca país. La expresión anglosajona "country of origin effect" (efecto del país de origen) representa, con certeza, una de las vinculaciones más claras que se establecen entre marcas comerciales y marcas de territorio. La revisión de la literatura muestra que, si bien el territorio y la marca comercial se retroalimentan en beneficio mutuo en todo este proceso, siempre es la marca comercial la que fija el atributo - a menudo estereotipado - a partir del cual reconocer e identificar un territorio (puntualidad suiza, glamur francés, elegancia italiana, precisión alemana o tecnología japonesa, por poner algunos ejemplos). Por tanto, la marca comercial ha sido habitualmente preponderante en su vinculación con el territorio (San Eugenio, 2013, p. 154).

¿Cuál es la marca con la cual identifican al Perú? ¿Cómo los procesos penales en contra de cuatro expresidentes de la República inciden en la opinión pública nacional e internacional? En esa misma línea, ¿cómo impacta la presencia de los acuerdos de colaboración eficaz con representantes de la 
empresa Odebrecht que involucran a altas autoridades con actos de corrupción? Así, según el informe de 2019 de Transparencia Internacional, en el ranking anticorrupción, Nueva Zelanda está en primer lugar, seguida de países como Dinamarca, Suiza, Suecia y Finlandia; en cambio, Perú se ubica en el puesto 101 de ciento ochenta países, ocupando el último puesto Somalia. En Suramérica, países peores posicionados que el Perú son Bolivia, Brasil, Paraguay y Venezuela.

¿Cómo mejorar? ¿Cómo evitar que Perú sea conocido como país corrupto? Claro que el cohecho genera un daño moral al país, en su imagen, en su reputación, en su marca como país, y el perito evaluador lo tendrá que tomar en cuenta a la hora de cuantificar el monto de la indemnización; para ello, una fuente de información es la que nos proporciona Futurebrand, una consultora global de marca e innovación que maneja un ranking de setenta y cinco países, ubicando la marca Perú en el puesto 37, siendo superado, en Latinoamérica, solo por Argentina, país que está en el puesto 36. También está el ranking del Banco Mundial, que ubica al Perú en el puesta 49. En suma, el perito evaluador tendrá que manejar variables cuantitativas como cualitativas, utilizando métodos de valuación como el proceso analítico jerárquico, para determinar el monto indemnizatorio, por ejemplo, por daño moral, que Perú sufre a través de la corrupción.

\section{CONCLUSIONES}

El procurador no puede ser un invitado de piedra en el sistema judicial peruano, un abogado que solamente está a la expectativa de lo que la Fiscalía pueda argumentar y demostrar al juzgador, y cuando este último le pregunta al abogado del Estado: “Algo que agregar?”, es inconcebible que conteste: "Nada señor juez, me adhiero a lo manifestado por el Ministerio Público".

La lucha contra la corrupción exige abogados del Estado expertos en el tema, que tengan la habilidad de construir su teoría del caso por medio de instrumentos epistémicos como la gestión de la prueba, la imputación del daño y la pericia de evaluación de daños.

Así, por gestión de la prueba entendemos a aquella estrategia de recolección y procesamiento de la información para efecto de realizar un razonamiento de corte epistémico sobre los hechos comunicados en la noticia criminal. Ello implica la experticia del procurador en identificar las afirma- 
ciones fácticas susceptibles de ser conectadas a un tipo penal de cohecho, o en su defecto a otro pragma típico. Asimismo, la habilidad de conectar con su equipo de investigadores y peritos para la construcción de la imputación del daño. Y, por imputación del daño entendemos la precisión del marco fáctico, circunstanciado en tiempo, modo y lugar, cuya explicación, con claridad y sencillez, se desprenda de las evidencias. Esta precisión, a su vez, debe permitir conocer los elementos configuradores del cohecho, pero, sobre todo, las consecuencias dañosas a los intereses del Estado, que hemos indicado en el presente trabajo y que se actualizan tanto en daños tangibles como intangibles, así como el lucro cesante.

Igualmente, se requiere recurrir a la valuación económica como instrumento forense para la cuantificación de la indemnización, que es el objetivo fundamental del procurador en los procesos penales anticorrupción. En esa inteligencia, la valuación es la ciencia aplicada que tiene como objetivo la determinación del valor de los daños, tangibles e intangibles, lo que se entiende como daño emergente, incluyendo el lucro cesante y los conceptos de indemnización señalados en la norma legal respectiva, teniendo en cuenta los elementos de comparación, las características o variables explicativas que lo caracterizan y el entorno económico-temporal en que se encuentra, mediante la utilización de un método contrastado de cálculo aplicado por un tasador o valuador profesional, y que permita al experto incorporar tanto el conocimiento objetivo y las variables cuantitativas como el conocimiento subjetivo y las variables cualitativas.

Esto se traduce en la pericia de evaluación de los daños, la cual parte de la identificación de los daños que el cohecho ha generado a los intereses estatales, como serían los casos de daños materiales, lucro cesante, daño a la marca Perú, entre otros supuestos, para efecto de coadyuvar con la administración de justicia para la determinación del monto indemnizatorio; así, esta cuantificación es el producto de fórmulas matemáticas que han procesado los datos a través de paquetes estadísticos; datos que han sido obtenidos mediante criterios cuantitativos como cualitativos, donde el perito, quien puede ser un matemático, un contador, un ingeniero, un economista, un arquitecto, o incluso un abogado, tiene que contar con la suficiente experticia en la valuación para justificar su trabajo forense. Lamentablemente, lo señalado en el presente estudio está alejado del trabajo que en la actualidad los procuradores anticorrupción vienen realizando en el país; por un lado, por la carencia de peritos valuadores en la Procuraduría y, por otro, por la 
falta de experticia entre los propios abogados del Estado en el manejo de constructos como la teoría del delito, la teoría de la prueba y el razonamiento jurídico, lo cual impacta en una deficiente imputación del daño, dado que se limitan al artilugio de "afectación al ordenamiento jurídico" para justificar la reparación civil en los delitos de peligro, recayendo en los fiscales toda la responsabilidad epistémica para lograr decisiones judiciales apegadas al derecho que coadyuven al combate de la corrupción.

En suma, se espera que el presente trabajo genere reflexiones entre nuestros operadores, que permitan advertir que, ante una criminalidad especializada, como es la corrupción, se requiere de herramientas tanto como de investigaciones epistémicas, también especializadas, debiendo generar un perfil no solamente para los jueces y los fiscales anticorrupción, sino también para los procuradores, que como abogados del Estado son los llamados a defender los intereses estatales. 


\section{REFERENCIAS}

Acale, M. (2002). Los delitos de mera actividad. Revista de Derecho Penal y Criminología, (10), 11-45.

Aedo, C. (2014). El concepto de culpa aquiliana y su evolución en las últimas décadas. Distintas Teorías. Revista de Derecho de la Universidad Católica del Norte, 21(2), 21-59.

Alterini, A., Ameal, O. y López R (1995). Derecho de obligaciones, civiles y comerciales. Abeledo-Perrot.

Aznar, J. y Guijarro, F. (2012). Nuevos métodos de valoración. Modelos multicriterio. Universitat Politécnica de Valencia.

Bárcena, R. (2012). La causalidad en el derecho de daños. Universitat de Girona.

Benavente, H. (2011). La aplicación de la teoría del caso y la teoría del delito en el proceso penal acusatorio. J. M. Bosch.

Benavente, H. (2017). Prueba y recursos. Flores.

Bunge, M. (1985). La investigación científica. Ariel.

Castejón, F. (1948). La responsabilidad sin culpa en los derechos civil y penal. Anuario de Derecho penal y Ciencias Penales, 1(03), 477-492.

Coloma, R. (2017). Conceptos y razonamientos probatorios. Revista de Derecho de la Universidad de Valdivia, 30(2), 31-56.

Cupis, A. (1975). El daño. Bosch.

Estrella, Y. (2009). El nexo causal en los procesos por responsabilidad civil extracontractual. Universidad Nacional Mayor de San Marcos.

Fernández, G. (2005). De la culpa ética a la responsabilidad subjetiva: ¿el mito de Sísifo? Panorámica del concepto y del rol de la culpa en el derecho continental y en el código civil peruano. Revista Themis, (50), 237-272.

Ferrer, J. (2013). Estándares de prueba y prueba científica. Ensayos de epistemología jurídica. Marcial Pons.

Ferrer, J. (2018). Filosofía del derecho privado. Marcial Pons.

González, D. (2003). Hechos y argumentos. Racionalidad epistemológica y prueba de los hechos en el proceso penal. Jueces para la democracia. Información y Debate, (46), 17-26.

Laudan, L. (2007). Aliados extraños. La inferencia a la mejor explicación y el estándar de prueba penal. Anuario de Filosofía y Teoría del Derecho, (1), 305-327. 
Laudan, L. (2013). Verdad, error y proceso penal. Un ensayo sobre epistemología jurídica. Marcial Pons.

Leysser, H. (2020). El daño al proyecto de vida colisiona con la constitución. Repaso sobre (y repase de la jurisprudencia peruana contra) un concepto no resarcible. Revista Gaceta Civil \& Procesal Civil, (80), 11-48.

López, J. (1964). Notas sobre el sistema de responsabilidad del Código Civil. Balance de un siglo. Revista Jurídica de Buenos Aires, (1), 59-65.

López, J. (1978). Esencia y fundamento de la responsabilidad civil. Revista de Derecho Comercial y de las Obligaciones, (11), 10-21.

Mata, N. (2006). El bien jurídico protegido en el delito de cohecho. La necesidad de definir el interés merecedor y necesitado de tutela en cada una de las conductas típicas encuadradas en los que se conoce, demasiado genéricamente, como ámbito de la corrupción. Revista de Derecho Penal y Criminología, (17), 81-152.

Nieva, J. (2018). La carga de la prueba: una reliquia histórica que debiera ser abolida. Revista Ítalo-Española de Derecho Procesal, (1), 129-145.

Pérez, C. (2017). El dolo eventual y la culpa consciente en los accidentes automovilísticos: la perspectiva del derecho penal argentino. Revista Jurídica, 13(1), 213-232.

Prütting, H. (2010). Carga de la prueba y estándar probatorio: la influencia de Leo Rosenberg y Karl Hainz Schwab para el desarrollo del moderno derecho probatorio. Revista Ius et Praxis, 16(1), 453-464.

Quintano, A. (1957). Diferenciación entre la culpa civil y la culpa criminal. Anuario de Derecho Civil, 10(4), 1039-1056.

Ragués, R. (2013). Mejor no saber. Sobre la doctrina de la ignorancia deliberada en derecho penal. Revista Discusiones, (13), 11-38.

Reyna, L. (2011). El objeto de tutela penal en el delito de cohecho. Revista Gaceta Penal y Procesal Penal, (23), 118-126.

Rodríguez, M. (2012). Manual de casos penales. La teoría general del delito y su importancia en el marco de la reforma procesal penal. Cooperación Alemana al Desarrollo Internacional.

Rodríguez, E. (2015). Metodología de la investigación. Universidad Juárez Autónoma de Tabasco.

Rueda, M. (2001). La teoría de la imputación objetiva del resultado en el delito doloso de acción. Una investigación, a la vez, sobre los límites ontológicos de las valoraciones jurídico-penales en el ámbito de lo injusto. Bosch. 
Salas, J. (2015). El modelo de valuación inmobiliaria en México. Revista Iberoamericana para la Investigación y el Desarrollo Educativo, 5(10), 1-25.

San Eugenio, J. (2013). Del Estado-nación al Estado-marca. El rol de la diplomacia pública y la marca del país en el nuevo escenario de las relaciones internacionales. Revista de Estudios Sociales, (46), 145-157.

Valeije, I. (1996). El tratamiento penal de la corrupción. El delito de cohecho. Edersa.

Villanueva, E. (2017). Análisis de la reparación civil en los delitos de peligro abstracto. Los problemas del daño civil en el Acuerdo Plenario N. ${ }^{\circ} 6-$ 2006/CJ-116. Revista Gaceta Penal \& Procesal Penal, (98), 45-67.

Zaffaroni, E. (2007). Manual de derecho penal. Parte general. Ediar. 